\title{
Strategies to Influence a Quality and Compliance Culture
}

\author{
Betsy Macht \\ Walden University \\ Anne Davis \\ Walden University
}

\begin{abstract}
Sales of defective or substandard products carry a potential risk of unintended effects on the consumer. The purpose of this single-case study was to explore the strategies to influence a culture of quality and compliance. Findings identified the value of weaving quality and compliance into a unified matrix to establish a holistic approach to endowing the organizational culture with the behaviors and habits that drive quality and compliance across business unit boundaries. To treat any aspect of quality and compliance as a separate element of the culture may undermine the overall effectiveness of quality and compliance programs, leaving room for employees to doubt the value top leadership places on these requirements.
\end{abstract}

Keywords: quality, organizational culture, habits, compliance, TQM

\section{Introduction}

The ability of a manufacturer to produce products that meet quality and compliance requirements ensures their ability to meet customer demand and be profitable (Mesut, Özsoy, \& Aksu, 2015). Manufacturers starting out in business identify the parameters that define a salable product, and seek to define the culture, materials and components, and manufacturing processes that consistently produce salable products (Korkofingas \& Ang, 2011). These product parameters define the quality of the products offered to consumers and establish the basis for managing compliance (Korkofingas \& Ang, 2011). Two attributes of quality and compliance include proactive actions to ensure product quality and regulatory compliance, and reactive actions in response to product and compliance nonconformance issues (Foster, 1998; Lin, Chu-hua, \& Kang-Wei, 2013) that ensure production of marketable products, meeting customer demand, and being profitable.

In 2013, the U.S. Department of Justice (2014) issued over $\$ 450$ million in fines to major pharmaceutical companies for health care violations covering product and manufacturing process related issues. Fines from regulatory agencies increase business costs with a goal to drive organizations to better ensure that the products sold meet customer expectations (Liu \& Xiong, 2015; Roman, 2014). The use of a quality management system (QMS) improves product quality providing clear guidance to employees on work performance (Hongyan \& Yanan, 2014). In addition, a QMS unites the culture by embedding quality and compliance principles, ensures that products meet specifications and comply with applicable regulations, and drives production of marketable products that meet customer demand and secures business profitability (Doyle, McGovern, \& McCarthy, 2014; Weingarten, Fynes, Cheng, \& Chavez, 2013).

Hofmann and Oldehaver (2016) noted the need for a high commitment to product quality. Without this commitment, an enterprise may produce substandard products, driving business risks higher, and in drug, medical, and consumer healthcare products, increasing the possibility of unintended 
side effects and health affects (Hofmann \& Oldehaver, 2016). Schmiedel, vom Brocke, and Recker (2013) posited that the four core values of customer orientation, excellence, responsibility, and teamwork guide the development of a culture. These core values create the link between a quality culture and effective business process management (Schmiedel et al., 2013). An effective organizational culture integrates three characteristics, including consistency across cultural indicators, a consensus among organizational members, and a focus on leaders as culture creators (Green, 2012). While Schmiedel et al. (2013) and Green (2012) chose different words to describe the key factors, they both emphasized the need for an effective organizational culture to incorporate similar behaviors where excellence aligns to consistency, responsibility aligns to leadership, and organizational consensus aligns to teamwork. To embed a culture of quality, leaders need to establish work routines and habits linking quality to organizational performance (Polites \& Karahanna, 2013), ensuring that employees utilize internal procedures and adhere to quality processes. Neal, Wood, Labrecque, and Lally (2012) posited that there is a positive behavioral association in relation to goals and actual habit performance, and a nonlinear relationship between the influences of goals on habit performance.

A quality product needs to meet consumer expectations, product specifications, and health authority regulations (Doyle et al., 2014; Tzavara \& Heritier, 2012; Weingarten et al., 2013; Zehir, Ertosun, Zehir, \& Müceldilli, 2012). When a product does not meet specifications, it will not meet customer expectations or health authority regulations, potentially resulting in regulatory citations, fines, and product recalls (Doyle et al., 2014; Tzavara \& Heritier, 2012). Ensuring product quality and compliance requires that manufacturers invest in processes that ensure products sold meet customer expectations (Liu \& Xiong, 2015; Roman, 2014). These same processes must encourage employees to adopt the habits and behaviors that embed a culture of quality and compliance.

To ensure a culture of quality, leaders and employees require an understanding of the behaviors and habits that embed a culture of quality into the organization (Rashid \& Aslam, 2012). Rashid and Aslam identified the need to reward employees who identify opportunities for product and process improvement as a means to institute a culture focused on continuous improvement. Business leaders also need information on how to ensure compliance by integrating health authority regulations and standards into the organizational culture while maintaining a high level of employee performance and manufacturing productivity (Valmohammadi \& Roshanzamir, 2015). There can be a tension between complying with regulatory requirements and promoting innovation in a production environment.

This article addresses the research question: what strategies influence quality and compliance in an organization assuring production of marketable products and meeting customer demand? The experiences of business leaders within an enterprise who are engaged in embedding a culture of quality and compliance formed the basis for the interview questions for this study. The conceptual framework was the theory of constraints (TOC) developed by Goldratt in 1992. The TOC model assists employees in manufacturing operations to analyze process constraints and identify process improvement opportunities (Naor, Bernardes, \& Coman, 2013). Improving performance by eliminating the constraints affecting product quality allows manufacturing employees to produce products that meet quality and compliance requirements, which satisfies market demands and achieves the ultimate goal of making money (Gupta, Gurjeet, \& Chahal, 2013; Pacheco, 2014). By applying Goldratt's (1992) five steps, employees can facilitate a process of analysis that drives process improvement through the elimination of system constraints and thus eliminating the need for redesign of an entire process or system. 


\section{Linking Culture to Other Aspects of Quality}

Issues with product quality and product risk may result in negative impacts to business, social, and professional elements including business reputation, challenges to business sustainability that impact local communities, and constraints on the treatments and healthcare products available to consumers. When recalled from the market, defective products result in lost revenue, potentially increased product liabilities, and decreased customer satisfaction (Garstenauer, Blackburn, \& Olson, 2014; Hofmann \& Oldehaver, 2016; Rosencrance \& Wu, 2015). These product quality issues affect brand equity and long-term market share, and may influence business survival due to lost sales (Nagaich \& Sadhna, 2015; Rosencrance \& Wu, 2015).

Business survival ties directly to community stability ensuring a sustainable source of local employment, and enabling stability and growth. Globalization has increased awareness of product quality issues, and increases the vulnerability of businesses (Nagaich \& Sadhna, 2015; Rosencrance $\& \mathrm{Wu}, 2015)$. This increased awareness among global customers necessitates that businesses must remain competitive on product price and quality while delivering compliant products to the market (Nagaich \& Sadhna, 2015; Rosencrance \& Wu, 2015).

To establish a quality culture requires integration of organizational norms and values that drive business processes and strategy (Alotaibi, Yusoff, \& Islam, 2013). In competing for a share of the market, a business should remain focused on product quality, in addition to product cost, to meet customer expectations (Schmiedel et al., 2013). Product quality and value both play a role in business survival where customer trust in a product's performance can link to future sales (Maurer, 2013). While price potentially influences customer purchase decisions, price may also influence customer perception of quality (Lalwani \& Shavitt, 2013). Lalwani and Shavitt (2013) found that if, after the initial purchase, a product did not meet customer expectations, the link between pricing and perception of quality was severed diminishing consumer tendency to repeat the purchase.

Employee ideas to improve the product and reduce cost complement a business strategy ensuring success (Choi, Lee, \& Yoo, 2010); however, product innovation should not negatively affect product quality. Business leaders should create a culture integrating the values and norms for both product quality and employee innovation (Wagner et al., 2014). Barriers to successful implementation of a quality culture include a perception of a lack of value, a lack of time and financial resources, insufficient leadership commitment, and ineffective training across the employee population (Davis et al., 2014). An organizational culture that supports employee innovation reflects a more mature QMS that uses formal protocols, establishes rules, and provides incentives in support of creating a culture of quality (Wagner et al., 2014). When setting a goal to establish a culture of continuous quality improvement an organization needs to move away from periodic, project centered cycles to an end-to-end business model that embraces a culture of quality (Davis et al., 2014). When transforming an organizational culture, leaders need to identify the barriers to success. These barriers may include changing perceptions regarding priorities, time management, lack of capabilities in quality tools and methodologies, and lack of leadership (Davis et al., 2014).

\section{Knowledge Management}

Organizational knowledge is unique and difficult to reproduce adding value to the distinctiveness of a business (Biotto, De Toni, \& Nonino, 2012) and fitting into Porter's (2008) five forces business strategy. If effectively harnessed, the interactions and innovations derived from this knowledge may offer an enterprise a competitive advantage. The common memory established through explicit and tacit knowledge within an enterprise can differ in terms of understanding and consistency in 
application across organization (Goujon, Didierjean, \& Poulet, 2013). The need to ensure uniformity in understanding and application of standardized procedures that ensure compliance is a challenge for leaders. Leaders need to eliminate barriers to knowledge sharing to enhance enterprise culture, reduce duplication, and stimulate innovation within and between organizations (Qureshi \& Evans, 2015). Qureshi and Evans identified the need to differentiate the two categories of shared knowledge including the more easily shared explicit knowledge, and the harder to share tacit knowledge.

In studying the performance of teams and organizations, Choi et al. (2010) observed that team norms and behaviors integrated into daily work practices. Choi et al. concluded that investment in information systems enhanced explicit and tacit knowledge sharing and application, resulting in improved team performance and compliance. Leaders may create a positive relationship between quality and culture from the perspective of organizational learning and innovation (Long, Abdul Aziz, Kowang, \& Ismail, 2015). Choi et al. (2010) concluded that to create a competitive advantage and sustain compliance, the shared knowledge should identify opportunities for continuous process improvement and product innovation.

\section{Habit}

Habit may play a positive or a negative role providing an opportunity for leaders to establish strategies reinforcing the positive habits necessary to produce marketable products. Liu-Thompkins and Tam (2013) examined the link between attitudinal loyalty and habit with regard to repeat behaviors. Purchasing decisions made through feelings of loyalty and purchasing decisions made based on habit were both important to consumers repurchase decisions; however, the Liu-Thompkins and Tam (2013) did not show a strong link between those two factors. The results indicated the potential for habit to play a more important role in repurchase decisions depending on the industry (Liu-Thompkins \& Tam, 2013).

To create a culture of quality, behaviors need to align to quality and compliance requirements and become integrated as habits within the organization (Polites \& Karahanna, 2013). Leaders should establish and reinforce the repetitive behaviors needed to embed a culture of quality and compliance. Modifying work routines to include new behaviors helped to accelerate integration of the new behaviors into organizational norms and habits (Polites \& Karahanna, 2013). With appropriate intervention strategies in place to disrupt organizational systems from settling back into established norms, Polites and Karahanna indicated that the organizational changes were likely to become sustainable.

With the digital technologies, networks, and social media available there is the opportunity to influence habits through messages received by individuals anytime and anywhere (Giraudo \& Hugo, 2014). In examining the link between mechanisms that trigger habits and habits in daily life, Neal et al. (2012) concluded that behavior frequency and context might influence habit strength. Leaders who develop strategies to embed a culture of quality need to consider the strength of the habits desired in the organization (Neal et al., 2012).

Specific cues within the organization trigger habits and an associated behavior establishing a potential link to behaviors influencing organizational routines and culture (Neal et al., 2012). Leaders may need to consider the degree of specificity of quality and compliance goals versus the types of behaviors they wish to embed in a quality culture (Greaves et al., 2013). In addition to understanding the factors that influence behavior and habit, business leaders should understand the factors influencing how employees freely and consciously follow operating procedures designed to deliver quality and compliant products. A leader should set strategies to ensure that employees 
become conscious of the requirements to deliver quality and compliant products, and should be willing to implement those requirements in achieving business goals and producing marketable products.

Winter (2013) linked the routines and capabilities in an enterprise to organizational culture to explore how the treatment of individuals links to organizational routines and capabilities, and how to maximize an individual's capability to make a rational choice and to contribute. The interrelationships identified by Winter between these factors explained how individuals make decisions in an organization, and how employees will need to forget old habits, replacing them with new habits. Chiu, Hsu, Lai, and Change (2012) found trust linked habits and repeat behaviors. When a strong habit exists, the individual's intention to take action connects to past behavior instead of attitude (Chiu et al., 2012). Just as retailers look for a repeat habit of shopping at their store, leaders in pharmaceutical and medical device manufacturers look for a repeat habit of following established procedures and regulations (Al-Bourini, Al-Abdallah, \& Abou-Moghli, 2013; Chiu et al, 2012).

\section{Organizational Effectiveness}

In a study of the connection between organization size and performance, Taylor and Taylor (2014) considered six success factors that influence performance measurement, including organizational learning in a quality management culture. In the findings from the study, Taylor and Taylor reinforced the criticality of firm leadership on quality management, regardless of the size of the enterprise. Zelnik et al. (2012) examined the link between employee understanding of a QMS and the leadership behaviors needed to drive employee understanding. Zelnik et al. identified a positive link between top management attitudes toward the QMS and employee general satisfaction providing the basis for understanding why a QMS adds value. Taylor and Taylor (2014) and Zelnik et al. (2012) identified a link between the leadership behaviors necessary to influence employee performance and ensure successful integration of the organizational habits associated with quality management. Leadership strategies that drive consistent delivery of marketable products need to consider how to influence organizational effectiveness and team performance.

Rai (2011) explored the link between organizational culture and knowledge management (KM) in organizations based on the belief that a critical link existed between organizational culture and KM in organizations. Rai developed a framework to use in understanding how organizational culture drives improvement and effectiveness. To continue to improve, the organization should learn from mistakes, taking action, and performing analysis to eliminate the cause of the mistake (Rai 2011). Rai built on the research of Valmohammadi and Roshanzamir (2015) identifying the need for research to further explore the relationship between organizational culture and organizational effectiveness. Valmohammadi and Roshanzamir studied the connection between organizational culture, total quality management (TQM), and organizational effectiveness, which complements the research by Rai (2011) on organizational culture and KM, and the factors driving improvement. Valmohammadi and Roshanzamir (2015) identified culture as a shared collective structure and a characteristic of the work unit where a positive link existed between culture, TQM, and organizational performance.

Other findings by Loke, Downe, Sambasivan, and Khalid (2012); Taylor and Taylor (2014); and Zelnik et al. (2012) identified leadership as a key factor in establishing a quality improvement culture, strategic planning as necessary to ensure appropriate allocation of resources to quality, and leadership support for solving problems, and making decisions to assist the enterprise in embedding a culture of quality. Malik and Blumenfeld (2012) examined the association between commitment to 
quality and information sharing, continuous improvement, and team work, and identified a positive connection between the integration of quality management practices, including quality culture and organizational learning. Moreover, Malik and Blumenfeld concluded that a surface-level commitment to quality management practices will not allow these programs to realize their full potential unless there is a leadership commitment to learning, open-mindedness, and shared learning. In addition to understanding the factors that influence behavior and habit, business leaders should understand the factors influencing how employees freely and consciously follow operating procedures designed to deliver quality and compliant products. A leader should set strategies to ensure that employees become conscious of the requirements to deliver quality and compliant products, and should be willing to implement those requirements in achieving business goals and producing marketable product.

\section{Study Design, Description, and Parameters}

The study company was selected as an exemplar of quality products with a recognized culture of quality and compliance excellence. Through a branded program, the study organization integrated product quality and compliance into a holistic approach integrating business, quality, and compliance drivers into a unified organizational platform. Practices such as obtaining global certifications and independent governance audits ensure that the study company sustains their commitment to a culture of quality and compliance. These practices include U.S. Food and Drug Administration's (2018) good manufacturing practices certification and International Organization for Standardization's (ISO) certifications for (a) their global QMS under ISO 9001 (ISO, n.d.) and (b) certification for the development of a QMS that provides for continual improvement, emphasizing defect prevention and the reduction of variation and waste across the supply chain.

In this research study, certain weaknesses and limitations existed. A weakness to the study was the focus on a single site. This limitation encompassed a limited number of participants from one enterprise. Although the sample size was sufficient for a qualitative case study, capturing the lived experiences of one enterprise may not be sufficient to ensure transferability across other sites and industries. A limitation of the study was the decision not to focus specifically on TQM tools, methods, or related certification processes. Many studies have been conducted focusing on TQM and using the quantitative method. For this study, we wanted to identify those factors that went beyond TQM to explore the human factors that influence a culture of quality and compliance using the qualitative method.

Participants' experiences were explored following the qualitative method, using a single-case study with homogeneous, purposive sampling. The participant pool consisted of quality and compliance directors, managers, and technical leaders with a minimum of 5 years of experience at one company. Consistent with the recommendation of Daniel (2012), the purposefully selected employee participants had an intimate knowledge of the quality and compliance requirements for the study company ensuring their ability to respond to the interview questions. Using homogeneous purposive sampling for selection of participants from one enterprise allows the researcher to use a smaller sample population to engage in an in-depth exploration of the phenomena under study (Hyett, Kenny, \& Dickson-Swift, 2014). In addition, Palinkas et al. (2013) posited that use of homogeneous sampling reduces variation. To reduce variation, participants were selected from a specific division of the study company with roles in quality, compliance, operations, and corporate governance.

The qualitative methodology emerged as early as 1925 as a tool for researchers interested in exploring and understanding human behavior (Bailey, 2014). Use of the qualitative research method applies when the researcher focuses on the how, who, and why of organizational processes (Percy, 
Kostere, \& Kostere, 2015; Yin, 2013). To understand the dynamics of the workplace and the factors that influenced product quality required interaction with the study subjects. To understand the social and professional interactions of the work place, the researcher needs to pay attention to employee opinions and experiences (Cronin, 2014). The qualitative, single-case study method suited this type of research that explored the strategies leaders need to use to embed a culture of quality ensuring production of marketable products, meeting customer demand, and being profitable. Reliability and validity of the findings was ensured through the use of a case study protocol, pilot test of the study questions, an interview protocol, member checking, and triangulation.

Per the recommendation of Baškarada (2014) and Ingham-Broomfield (2015), data analysis occurred in parallel with data collection allowing for adjustments to the coding to enhance the research process. Based on recommendations posited by Baškarada (2014), Ingham-Broomfield (2015), and Snyder (2012), an initial list of codes was created at the start of the data gathering process based on the literature review. Using a continuous cycle of data generation, coding, and analysis, as posited by Baškarada (2014) and Finfgeld-Connett (2014), the lists of codes was updated to reflect emerging patterns and outlying variations.

\section{Description of the research methods and data analysis plans.}

Based on the work of Cronin (2014) and Yin (2014), multiple data sources were used. Data collection included one-on-one, telephone-based, semistructured interviews that typically lasted $40 \mathrm{~min}$ per participant, with some lasting $60 \mathrm{~min}$. Additional data was obtained through onsite observations; from company accessible documentation including the 2014 annual report, the supplier code of conduct document, the product stewardship training requirements document, the combined organization chart for the global industrial and supply chain department, corporate social responsibility training curriculum, and the product safety code strategy document and from publically available compliance information including the 2014 health, safety, environment, and quality policy; the 2013 sustainable development report; the 2016 product responsibility statement; the 2016 Responsible Care statement; and the 2016 [branded program] statement.

Ten leaders from a chemical intermediates supplier located in the United States participated in interviews, enabling an in-depth exploration of the strategies used to embed a culture of quality within their organization. While data saturation was reached at five interviews, interviews were continued with all 10 participants in the planned study group. Additional data sources for methodological triangulation included observations during a tour of the headquarters site, and analysis of policies, procedures, annual reports, and publically available information. The steps followed for the data analysis included transcription, cyclical review for themes and issues, coding, and synthesis.

\section{Research Findings}

The major themes and subthemes identified supported the research question and included leadership, culture and habits, communications, training, and management systems. All but one of the participants agreed on all themes. These themes align to the conceptual framework used for this study, the TOC, reinforcing the need to identify and remove barriers throughout the organization to embed a culture of quality and compliance.

The findings described the leadership role of management in the organization; participants described the global branded program that served as a framework to establish their way of doing business as a critical strategy that sets the global standard for quality and compliance. Executive leadership 
within the study company formally adopted a branded program establishing their way of doing business with quality and compliance positioned as a primary behavior. All participants discussed the importance of habits as a vital aspect of their culture of quality and compliance.

Barriers to successful implementation of a quality culture include a perception of a lack of value, a lack of time and financial resources, insufficient leadership commitment, and ineffective training across the employee population (Davis et al., 2014). Findings identified the value of weaving quality and compliance into a unified matrix to establish a holistic approach to endowing the organizational culture with the behaviors and habits that drive quality and compliance across business unit boundaries. To treat any aspect of quality and compliance as a separate element of the culture may undermine the overall effectiveness of quality and compliance programs, leaving room for employees to doubt the value top leadership place on these requirements.

Participants discussed the value of clear communications between organizational departments and customers to ensure quality and compliance. Participants described the use of different communications methods such as training, product safety data sheets, one-to-one coaching, attendance at business unit meetings, and direct engagement with customers. In addition, participants identified the processes used to inform partners of requirements, and to seek input about real or perceived constraints. These communications processes used by the study company targeted development and reinforcement of quality and compliance skills, acknowledging that there is always room for improvement.

Participants consistently identified management systems that included programs, data collection, and data analysis as one of the strategies used to embed a culture of quality and compliance. The importance of global management systems in providing a framework for quality and compliance was repeatedly discussed by participants, as well as, the Responsible Care program, product stewardship, manufacturing excellence, ISO standards, product and employee safety, and customer service as management systems important to ensuring quality and compliance. Note that participants did not focus on a single management system, but rather a combination of management systems.

After repeatedly reviewing the transcripts to identify repeat themes, further semantic analysis occurred using the Wordij (http://wordij.net/) software tool for text analysis. Wordij analyzes how the language used by interviewees in the transcripts, and the text documents collected, can express meanings. Wordij showed the relationships pictorially as a visual network. Garcia and Gluesing (2013) noted that by using a semantic analysis tool, researchers could organize the words and phrases to show biword connections. Analysis of the different word-based relationships identified during data analysis identified links between the data, the literature review, and conceptual framework showing strategies used to overcome constraints and identifying ongoing constraints requiring resolution. As shown in Figure 1, the Wordij analysis reinforced the findings uncovered through more traditional data analysis techniques. 


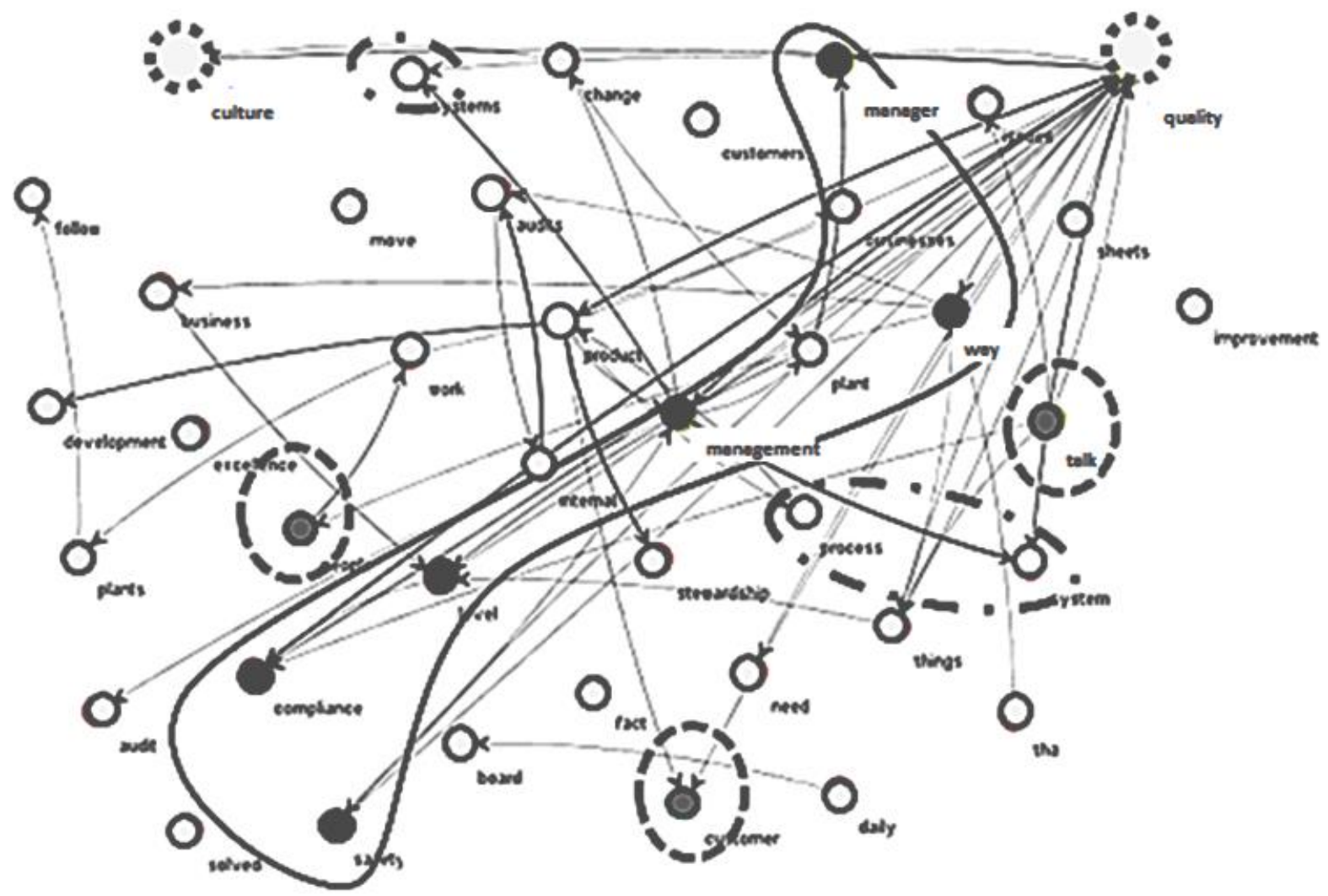

Figure 1. Wordij-Based Analysis Showing Word Relationships

\section{Conclusion}

In summary, several strategies were identified based on an analysis of the findings. Within the leadership theme, the strategy identified recommended that leaders should engage with internal employees, customers, and stakeholders to embed a culture of quality and compliance. The leaders in the study company expanded this notion to encompass quality, compliance, health, safety, and environment. To encourage the development of a culture and habits reinforcing a culture of quality and compliance, leaders should explore adoption of integrated quality and compliance platforms. Such platforms establish equal weight to quality, health, safety, environment, and process safety compliance in a harmonized corporate social responsibility platform. Communications strategies include targeted development and reinforcement of quality and compliance skills, acknowledging that there is always room for improvement, and asking questions and listening. The final strategy aligns to the management systems and data analysis theme. Based on the responses of the participants, leaders at the study company engage in activities that define performance frameworks and collect data to identify constraints to producing quality and compliant products. Within each of the management systems, participants described the opportunity to collect data that identifies constraints to eliminate to improve quality and compliance. 
Organizational capabilities align to specific and actionable skills that enable short-term success (de Brentani \& Kleinschmidt, 2015) building toward a sustainable culture. Such tools and skills enhance the ability of leaders to develop and implement strategies for manufacturing employees that embed a culture of quality. Use of these skills and strategies ensure that products sold meet quality and compliance requirements, deliver the intended effects, and ensure business profitability.

We recommend additional research of organizations or manufacturers with integrated quality and compliance platforms. Such platforms establish equal weight to quality, health, safety, environment, and process safety compliance in a harmonized corporate social responsibility platform. While top leaders know to set clear expectations, driving development of sustainable habits that enable crosscommunications between quality and compliance professionals and business unit leaders sets the framework for a culture of quality and compliance. Use of a qualitative research approach would provide an opportunity to explore the learned behaviors of employees and potentially identify suitable topics for quantitative research analysis to examine the phenomenon of a culture of quality and compliance.

We also recommend research using a qualitative research design to explore the lived experiences of employees in both the service and manufacturing sectors to capture their unique experiences. Additional research using a larger base of study participants would enable the researcher to better manage potential method bias and increase the reliability and validity of the study. These studies would allow capture of additional data on the strategies that influence a culture of quality and compliance enhancing the transferability of the results. We also recommend that researchers consider conducting similar studies on strategies for leaders to influence a quality and compliance culture using a broader group of case study organizations. A larger study group would allow the researcher to study strategies used by different enterprises and across different industries.

These findings may add value to businesses regulated by the U.S. Food and Drug Administration and other country-specific regulatory agencies by identifying the factors needed to embed an employee culture of quality and compliance. Rashid and Aslam (2012) explored the strategies needed to create and sustain a culture of quality, identifying the need to allow employees to engage in a process of continuous bottoms-up improvement across their supply chain. Roman (2014) noted that drug shortages resulting from a reduction of saleable products could affect the range and variety of treatments available to consumers. Aligning management and employees to a culture of quality and compliance may minimize fines and penalties incurred by organizations, increase profitability, eliminate possible drug shortages, and ensure production of products that meet consumer expectations.

Defective products, when recalled from the market, result in lost revenue, potentially increased product liabilities, and decreased customer satisfaction (Garstenauer et al., 2014; Hofmann \& Oldehaver, 2016; Rosencrance \& Wu, 2015). These product quality issues affect brand equity and long-term market share, and may influence business survival due to lost sales (Nagaich \& Sadhna, 2015; Rosencrance \& Wu, 2015). The sale of substandard products potentially create risks to public health from products that do not meet quality and compliance requirements including drug shortages and negative health impacts (Madadi, Kurz, Mason, \& Taaffe, 2014). In addition, shortages of drug and healthcare products potentially impact the quality of life achievable by consumers. Without a commitment to quality and compliance, an enterprise may produce substandard products driving higher business risks, and in drug, medical, and consumer healthcare products, increasing the possibility of unintended side effects and health affects (Hofmann \& Oldehaver, 2016). Key factors such as leadership behaviors and the habits of employees in the organization must align to create and sustain a culture of quality and compliance. 


\section{References}

Al-Bourini, F., Al-Abdallah, G., \& Abou-Moghli, A. (2013). Organizational culture and total quality management (TQM). International Journal of Business and Management, 8, 95-106. doi:10.5539/ijbm.v8n24p95

Alotaibi, F., Yusoff, R., \& Islam, R. (2013). Assessing the impact of total quality management practices and quality culture with competitiveness of Saudi contractors. American Journal of Applied Sciences, 10, 638-645. doi:10.3844/ajassp.2013.638.645

Bailey, L. (2014). The origin and success of qualitative research. International Journal of Market Research, 56, 167-184. doi:10.2501/IJMR-2014-013

Baškarada, S. (2014). Qualitative case study guidelines. The Qualitative Report, 19, 1-18. Retrieved from https://nsuworks.nova.edu/cgi/viewcontent.cgi?article=1008\&context=tqr/

Biotto, M., De Toni, A., \& Nonino, F. (2012). Knowledge and cultural diffusion along the supply chain as drivers of product quality improvement. The International Journal of Logistics Management, 23, 212-237. doi:10.1108/09574091211265369

Chiu, C., Hsu, M., Lai, H., \& Change, C. (2012). Re-examining the influence of trust on online repeat purchase intention: The moderating role of habit and it antecedents. Decision Support Systems, 53, 835-845. doi:10.1016/j.dss.2012.05.021

Choi, S., Lee, H., \& Yoo, Y. (2010). The impact of information technology and transactive memory systems on knowledge sharing, application, and team performance: A field study. MIS Quarterly, 34, 855-870. doi:10.2307/25750708

Cronin, C. (2014). Using case study research as a rigorous form of inquiry. Nurse Researcher, 21, 19-27. doi:10.7748/nr.21.5.19.e1240

Daniel, J. (2012). Sampling essentials: Practical guidelines for making sampling choices. Thousand Oaks, CA: Sage.

Davis, M., Mahanna, E., Joly, B., Zelek, M., Riley, W., Verma, P., \& Solomon Fisher, J. (2014). Creating quality improvement culture in public health agencies. American Journal of Public Health. 104, 98-104. doi:10.2105/AJPH.2013.301413

de Brentani, U., \& Kleinschmidt, E. J. (2015). The impact of company resources and capabilities on global new product program performance. Project Management Journal, 46, 12-29. doi:10.1002/pmj.21470

Department of Justice. (2014). Justice Department collects more than $\$ 8$ billion in civil and criminal cases in fiscal year 2013. Retrieved from https://www.justice.gov/opa/pr/justice-departmentcollects-more-8-billion-civil-and-criminal-cases-fiscal-year-2013

Doyle, E., McGovern, D., \& McCarthy, S. (2014). Compliance-innovation: Integrating quality and compliance knowledge and practice. Total Quality Management, 25, 1156-1170. doi:10.1080/14783363.2014.914641

Finfgeld-Connett, D. (2014). Use of content analysis to conduct knowledge-building and theorygenerating qualitative systematic reviews. Qualitative Research, 14, 341-352. doi:10.1177/1468794113481790

Foster, S. T. (1998). The ups and downs of customer-driven quality. Quality Progress, 31, 67-72. Retrieved from http://asq.org/qic/display-item/index.html?item=13289 
Garcia, D., \& Gluesing, J. C. (2013). Qualitative research methods in international organizational change research. Journal of Organizational Change Management, 26, 423-444. doi:10.1108/09534811311328416

Garstenauer, A., Blackburn, T., \& Olson, B. (2014). A knowledge management based approach to quality management for larger manufacturing organizations. Engineering Management Journal, 26, 47-58. doi:10429247.2014.11432028

Giraudo, F. J., \& Hugo, Z. M. (2014). Drug's information and publicity: A challenge for the pharmaceutical legislation. Pharmaceuticals Policy and Law, 16, 321-337. doi:10.3233/PPL140392

Goldratt, E. (1992). The goal: A process of ongoing improvement. Great Barrington, MA: North River Press.

Goujon, A., Didierjean, A., \& Poulet, S. (2013). The emergence of explicit knowledge from implicit learning. Memory \& Cognition, 42, 225-236. doi:10.3758/s13421-013-0355-0

Greaves, M., Zibarras, L., \& Stride, C. (2013). Using the theory of planned behavior to explore environmental behavioral intentions in the workplace. Journal of Environmental Psychology, 34, 109-120. doi:10.1016/j.jenvp.2013.02.003

Green, T. (2012). TQM and organizational culture: How do they link? Total Quality Management, 23, 141-157. doi:10.1080/14783363.2012.647847

Gupta, M., Gurjeet, K. S., \& Chahal, H. (2013). Improving market orientation: The theory of constraints-based framework. Journal of Strategic Marketing, 21, 305-322. doi:10.1080/0965254X.2013.790467

Hofmann, A., \& Oldehaver, G. (2016). Vertically linked industries, product quality and minimum quality standards. German Economic Review, 17, 92-103. doi:10.1111/geer.12067

Hongyan, J., \& Yanan, J. (2014). Application of improved entropy, catastrophe progression and set pair analysis method in extracting fuzzy rules of enterprise quality management system operation effectiveness. Journal of Chemical and Pharmaceutical Research, 6, 348-353. doi:10.21595/vp.2017.18937

Hyett, N., Kenny, A., \& Dickson-Swift, V. (2014). Methodology or method? A critical review of qualitative case study reports. International Journal Qualitative Studies on Health and Wellbeing, 9, 1-12. doi:10.3402/qhw.v9.23606

Ingham-Broomfield, R. (2015). A nurses' guide to qualitative research. Australian Journal of Advanced Nursing, 32, 34-40. Retrieved from https://www.researchgate.net/publication/273135487_A_nurses'_guide_to_Qualitative_Resea rch

International Organization for Standardization (ISO). (n.d.). ISO 9000 family-Quality management. Retrieved from https://www.iso.org/iso-9001-quality-management.html

Korkofingas, C., \& Ang, L, (2011). Product recall, brand equity, and future choice. Journal of Marketing Management, 27, 959-975. doi:10.1080/0267257X.2011.560717

Lalwani, A., \& Shavitt, S. (2013, August). You get what you pay for? Self-construal influences: Prices-quality judgments. Journal of Consumer Research, 40, 255-267. doi:10.1086/670034

Lin, C., Chu-hua, K., \& Kang-Wei, C. (2013). Identifying critical enablers and pathways to high performance supply chain quality management. International Journal of Operations \& Production Management, 33, 347-370. doi:10.1108/01443571311300818 
Liu, C. H., \& Xiong, W. (2015). Modelling and simulation of quality risk forecasting in a supply chain. International Journal of Simulation Modelling, 2, 359-370. doi:10.2507/IJSIMM14(2)C010

Liu-Thompkins, Y., \& Tam, L. (2013). Not all repeat customers are the same: Designing effective cross-selling promotion on the basis of attitudinal loyalty and habit. Journal of Marketing, 77(5), 21-36. doi:10.1509/jm.11.0508

Loke, S. P., Downe, A., Sambasivan, M., \& Khalid, K. (2012). A structural approach to integrating total quality management and knowledge management with supply chain learning. Journal of Business Economics and Management, 13, 776-800. doi:10.3846/16111699.2011.620170

Long, C. S., Abdul Aziz, M. H., Kowang, T. O., \& Ismail, W. K. W. (2015). Impact of TQM practices on innovation performance among manufacturing companies in Malaysia. South African Journal of Industrial Engineering, 26, 75-85. doi:10.7166/26-1-1038

Madadi, A., Kurz, M. E., Mason, S. J., \& Taaffe, K. M. (2014). Supply chain design under quality disruptions and tainted materials delivery. Transportation Research Part E, 67, 105-123. doi:10.1016/j.tre.2014.04.006

Malik, A., \& Blumenfeld, S. (2012). Six sigma, quality management systems and the development of organisational learning capability: Evidence from four business process outsourcing organizations in India. International Journal of Quality \& Reliability Management, 29, 7191. doi:10.1108/0265671121190882

Maurer, R. (2013). Building a quality culture one small step at a time. Journal for Quality \& Participation, 35, 8-11. Retrieved from https://secure.asq.org/perl/msg.pl?prvurl=http://asq.org/quality-participation/2013/01/changemanagement/one-small-step-at-a-time.pdf

Mesut, B., Özsoy, Y., \& Aksu, B. (2015). The place of drug product critical quality parameters in quality by design (QBD). Turkish Journal of Pharmaceutical Science, 12, 75-92. Retrieved from https://www.researchgate.net/publication/281925128_The_place_of_drug_product_critical_qu ality_parameters_in_quality_by_design_QBD

Nagaich, U., \& Sadhna, D. (2015). Drug recall: An incubus for pharmaceutical companies and most serious drug recall of history. International Journal of Pharmaceutical Investigation, 5, 1319. doi:10.4103/2230-973X.147222

Naor, M., Bernardes, E. S., \& Coman, A. (2013). Theory of constraints: Is it theory and a good one? International Journal of Production Research, 51, 542-554. doi:10.1080/00207543.2011.654137

Neal, D., Wood, W., Labrecque, J., \& Lally, P. (2012). How do habits guide behavior? Perceived and actual triggers of habits in daily life. Journal of Experimental Social Psychology, 48, 492498. doi:10.1016/j.jesp.2011.10.011

Pacheco, D. (2014). Theory of constraints and Six Sigma: Investigating differences and similarities for continuous improvement. Independent Journal of Management \& Production, 5, 331-343. Retrieved from https://www.researchgate.net/publication/263845571_THEORY_OF_CONSTRAINTS_AND_ SIX_SIGMA_INVESTIGATING_DIFFERENCES_AND_SIMILARITIES_FOR_CONTINUO US_IMPROVEMENT

Palinkas, L. A., Horwitz, S. M., Green, C. A., Wisdom, J. P., Duan, N., \& Hoagwood, K. (2013). Purposeful sampling for qualitative data collection and analysis in mixed method 
implementation research. Administration and Policy in Mental Health and Mental Health Services Research, 42, 533-544. doi:10.1007/s10488-013-0528-y

Percy, W. H., Kostere, K., \& Kostere, S. (2015). Generic qualitative research in psychology. The Qualitative Report, 20, 76-85. Retrieved from https://nsuworks.nova.edu/cgi/viewcontent.cgi?referer=http://scholar.google.com/\&httpsredir= $1 \&$ article $=2097 \&$ context $=$ tqr $/$

Polites, G., \& Karahanna, E. (2013). The embeddedness of information systems habits in organizational and individual level routines: Development and disruption. MIS Quarterly, 37, 221-246. doi:10.25300/misq/2013/37.1.10

Porter, M. (2008). The five competitive forces that shape strategy. Harvard Business Review, 86, 7893. Retrieved from https://hbr.org/2008/01/the-five-competitive-forces-that-shape-strategy

Qureshi, A. M. A., \& Evans, N. (2015). Deterrents to knowledge-sharing in the pharmaceutical industry: A case study. Journal of Knowledge Management, 19, 296-314. doi:10.1108/JKM09-2014-0391

Rai, R. K. (2011). Knowledge management and organizational culture: A theoretical integrative framework. Journal of Knowledge Management, 15, 779-801. doi:10.1108/13673271111174320

Rashid, K., \& Aslam, M. (2012). Business excellence through total supply chain quality management. Asian Journal on Quality, 13, 309-324. doi:10.1108/15982681211287829

Roman, A. (2014). The FDA and the pharmaceutical industry: Is regulation contributing to drug shortages? Albany Law Review, 77, 539-577. Retrieved from https://www.questia.com/library/journal/1G1-371969838/the-fda-and-the-pharmaceuticalindustry-is-regulation

Rosencrance, S. M., \& Wu, G. K. (2015). Advancing pharmaceutical quality oversight during the lifecycle of generic drug products. Journal of Generic Medicines, 12, 26-33. doi:10.1177/1741134315608909

Schmiedel, T., vom Brocke, J., \& Recker, J. (2013). Which cultural values matter to business process management? Business Process Management Journal, 19, 292-317. doi:10.1108/14637151311308321

Snyder, C. (2012). A case study of a case study: Analysis of a robust qualitative research methodology. The Qualitative Report, 17, 1-21. doi:10.4135/9781473915480.n61

Taylor, A., \& Taylor, M. (2014). Factors influencing effective implementation of performance measurement systems in small and medium-sized enterprises and large firms: A perspective from contingency theory. International Journal of Production Research, 52, 847-866. doi:10.1080/00207543.2013.842023

Tzavara, D., \& Heritier, A. (2012) Quality and environmental regulation: Verifying compliance along the supply chain. Business and Politics, 14, 1-22. doi:10.1515/1469-3569.1366

U.S. Food and Drug Administration. (2018). Facts About the Current Good Manufacturing Practices (CGMPs). Retrieved from https://www.fda.gov/Drugs/DevelopmentApprovalProcess/Manufacturing/ucm169105.htm

Valmohammadi, C., \& Roshanzamir, S. (2015). The guidelines of improvement: Relations among organizational culture, TQM and performance. International Journal of Production Economics, 164, 167-178. doi:10.1016/j.ijpe.2014.12.028 
Wagner, C., Mannion, R., Hammer, A., Groene, O., Arah, O.A., Dersarkissian, M., \& Suñol, R. (2014). The associations between organizational culture, organizational structure and quality management in European hospitals. International Journal for Quality in Health Care, 26, 17. doi:10.1093/intqhe/mzu027

Weingarten, F., Fynes, B., Cheng, E., \& Chavez, R. (2013). Taking an innovative approach to quality practices: exploring the importance of a company's innovativeness on the success of TQM practices. International Journal of Production Research, 51, 3055-3074. doi:10.1080/00207543.2012.752609

Winter, S. (2013). Habit, deliberation, and action: Strengthening the microfoundations of routines and capabilities. The Academy of Management Perspectives, 27, 120-137. doi:10.5465/amp.2012.0124

Yin, R. K. (2013). Validity and generalization in future case study evaluations. Evaluation, 19, 321332. doi:10.1177/1356389013497081

Yin, R. (2014). Case study research. Washington, DC: Sage.

Zehir, C., Ertosun, Ö., Zehir, S., \& Müceldilli, B. (2012). Total quality management practices' effects on quality performance and innovative performance. Procedia Social and Behavioral Sciences, 41, 273-280. doi:10.1016/j.sbspro.2012.04.031

Zelnik, M., Maletic, M., Maletic, D., \& Gomiscek, F. (2012). Quality management systems as a link between management and employees. Total Quality Management, 23, 45-62.

doi:10.1080/14783363.2011.637781

The International Journal of Applied Management and Technology (IJAMT), sponsored by Walden University's School of Management, is a peer-reviewed, online journal that addresses contemporary national and international issues related to management and technology. The objectives of the IJAMT are to: (a) encourage collaborative and multi-disciplinary examinations of important issues in business and technology management, and (B) engage scholars and scholar-practitioners in a dynamic and important dialogue.

Walden University Publishing: http://www.publishing.waldenu.edu 